\title{
DIÁLOGO INTERCULTURAL E RELAÇÕES INTERGRUPAIS NA EUROPA: CONTRIBUTOS DOS ESTUDOS Culturais a da Psicologia Social
}

\author{
Julia Alves Brasil \& Rosa Cabecinhas
}

\begin{abstract}
Resumo
Neste artigo discutem-se as contribuições dos Estudos Culturais e da Psicologia Social para as reflexões acerca dos desafios inerentes à promoção do diálogo intercultural na Europa, no contexto atual de relações intergrupais entre diversos Outros, propiciado por fatores como a intensificação dos fluxos migratórios e o avanço das tecnologias da informação e da comunicação. Para tanto, realizam-se articulações entre conceitos e categorias a partir de diferentes perspectivas teóricas nestes campos, de forma a associar discussões sobre processos identitários, alteridade, representações sociais, memória coletiva, assimetrias simbólicas, colonialidade do poder, do ser e do saber, a fim de (re)iniciar alguns debates sobre fenômenos complexos que se entrelaçam na construção do diálogo intercultural. Dessa forma, apresentam-se, ainda, diferentes concepções acerca dos conceitos de multiculturalismo e de interculturalidade, advogando-se a importância de uma perspectiva crítica na compreensão da interculturalidade, que a perceba como um projeto que parte das experiências dos "subalternos", a fim de buscar a transformação das estruturas sociais, institucionais e epistêmicas, (re)criando diferentes formas de ser, estar, de se relacionar, que impliquem não apenas o mero reconhecimento e tolerância de outras culturas, mas também a sua valorização, em diálogo e transformação mútuos.
\end{abstract}

\section{INTERCULTURAL DIALOGUE AND INTERGROUP RELATIONS IN EUROPE: CONTRIBUTIONS OF Cultural Studies and Social Psychology}

\begin{abstract}
This paper discusses the contributions of Cultural Studies and Social Psychology to the debates on the challenges inherent to the promotion of intercultural dialogue in Europe, in the current context of intergroup relations among several Others, facilitated by factors such as the intensification of migratory flows and the enhancement of information and communication technologies. To this end, we associate concepts and categories from different theoretical perspectives in these fields, in order to articulate discussions about identity processes, alterity, social representations, collective memory, symbolic asymmetries, coloniality of power, being and knowledge, to (re)initiate debates on complex phenomena that are intertwined in the development of intercultural dialogue. Therefore, different understandings about the concepts of multiculturalism and interculturality are presented, advocating the importance of a critical perspective in the understanding of interculturality, conceiving it as a project that starts from the experiences of the "subalterns", in order to seek the transformation of social, institutional and epistemic structures. This perspective allows people to (re)create different ways of being and relating to others, implying not only the mere recognition and tolerance of other cultures, but also their appreciation, in mutual dialogue and transformation.
\end{abstract}




\section{INTRODUÇÃo}

A "crise dos refugiados", o Brexit, o incremento do discurso de ódio na esfera pública e de partidos da extrema-direita na Europa são fenômenos que remetem para as tensões, contradições e complementaridades entre o local e o global (Beck, 2002), entre a valorização da diversidade cultural e a defesa exacerbada de uma alegada autenticidade. Se por um lado a valorização daquilo que é local e também o reconhecimento da diversidade dentro de um dado contexto cultural podem se configurar como possibilidades de combate a ideologias racistas e homogeneizadoras, por outro lado, elas também podem levar a localismos, conduzindo, ainda, à (re)produção de estereótipos sociais e de práticas discriminatórias dirigidas a diferentes Outros (Gros, 2002). Dessa forma, diante das transformações políticas, econômicas, tecnológicas e sociais ocorridas, sobretudo, no último século, vivemos num momento de pluralização das identidades nacionais e supranacionais (Hall, 2000), de alterações na organização das sociedades e de reformulações na noção de cidadania (Martins, Sidoncha, \& Bandeira, 2017). Conjuntura esta que nos convoca a refletir sobre como queremos e devemos (re)agir: a partir do erguimento de muros ou da construção de pontes? Momento em que nos cabe pensar sobre como a Europa, enquanto grupo supraordenado de pertença, se coloca neste cenário contemporâneo: como um espaço de possibilidade de existência de diálogo intercultural ou como um espaço de intensificação de assimetrias de poder e de mera tolerância dos diferentes Outros que fazem parte da região?

Neste artigo, discutimos sobre as possíveis contribuições dos Estudos Culturais e da Psicologia Social para estes debates. No âmbito dos Estudos Culturais (por exemplo, Canclini, 1999/2010; Hall, 1996, 2000), dialogamos especialmente com pressupostos dos Estudos Pós-Coloniais (por exemplo, Bhabha, 1990; Fanon, 1961/2004) e com a perspectiva decolonial (por exemplo, Maldonado-Torres, 2007; Quijano, 2005). Da Psicologia Social, recorremos sobretudo à Teoria da Identidade Social (Tajfel, 1982a, 1982b, 1983) e à Teoria das Representações Sociais (Moscovici, 1961/2004), além de discussões sobre memória coletiva (Licata \& Klein, 2005), relações intergrupais envolvendo grupos nacionais e supranacionais (Chryssochoou, 2000) e dinâmicas de aculturação (Berry, 2011).

Para tanto, o texto está estruturado da seguinte forma: primeiramente, tecemos algumas considerações sobre os Estudos Culturais e sobre suas diferentes perspectivas e desdobramentos em diferentes regiões; em seguida, discutimos sobre as principais convergências entre os Estudos Culturais e a Psicologia Social, a partir da apresentação das abordagens teóricas e de alguns conceitos centrais com os quais trabalhamos; finalmente, apresentamos algumas discussões acerca dos conceitos de multiculturalismo e de interculturalidade e apontamos possíveis caminhos para as reflexões acerca das relações intergrupais na Europa contemporânea e das condições necessárias para que ela se configure como um espaço de diálogo intercultural. 


\section{Considerações sobre os Estudos Culturais}

Os Estudos Culturais se constituem como um campo científico diversificado e, por vezes, controverso, de caráter interdisciplinar, que envolve diferentes áreas das Ciências Humanas e Sociais, como a Antropologia, as Ciências da Comunicação, as Ciências da Educação, os Estudos Literários, a História, a Geografia, a Psicologia, a Sociologia, entre outras. Configuram-se como formas de contestar narrativas prévias, que legitimam relações de poder e dominação, constituindo-se como possibilidades de (re)construir princípios teóricos e metodológicos que nos auxiliem no estudo das diferenças e da diversidade do nosso mundo (Hall, 2000). Portanto, mais do que uma disciplina "fechada", os Estudos Culturais colocam-se como um projeto caracterizado pela reflexão, crítica e contestação de diferentes conceitos e categorias, como cultura, identidade, poder, discurso, ideologia, hegemonia, entre outros, produzindo um conhecimento de cunho político, que visa à transformação social (Baptista, 2009; Barker, 2004).

Após o seu surgimento na Inglaterra, na década de 1950, os Estudos Culturais passaram a alcançar maior difusão nas décadas de 1960 e 1970, sobretudo a partir de trabalhos produzidos no Centro de Estudos Culturais Contemporâneos da Universidade de Birmingham (CCCS - Centre for Contemporary Cultural Studies), com autores como Stuart Hall. Assim, os Estudos Culturais passaram a englobar diversas áreas do conhecimento no estudo de diferentes aspectos das relações interculturais, de maneira que, especialmente no final da década de 1970, passaram também a ganhar maior destaque em diferentes partes do mundo os Estudos Pós-Coloniais e os Estudos Subalternos (Neves, 2009). Desse modo, desenvolveram-se investigações acerca das relações de subordinação e dominação entre diferentes culturas envolvidas nos processos de descolonização, principalmente a partir de obras de autores como Edward Said (1978/2007), Homi Bhabha (1990, 1994/2005), Frantz Fanon (1952/2008, 1961/2004) e Gayatri Spivak (1985/2010).

Os estudos desenvolvidos a partir dessas perspectivas passaram a se constituir como novos espaços (teóricos e políticos) de análise do mundo, de forma a possibilitar a superação de certas dicotomias, como a polaridade Ocidente/Oriente, discutida por Said (Prysthon, 2004). A partir dessas discussões, portanto:

cai o conceito de estado/nação e de identidade nacional pura, deixando o lugar a uma identidade híbrida e mestiça. As "grandes narrativas" são substituídas pela história das migrações pós-coloniais e da diáspora cultural e política que caracterizam a nossa actualidade. Os "esquecidos" levantam a cabeça e começam a falar, contando as suas histórias de marginalidade e de esquecimento. A cultura vira-se para "as margens" e transforma-se numa "praxe de sobrevivência". (...) Em suma, o colonialismo aparece cada vez mais como um conceito/chave fundamental para descodificar o presente. (Neves, 2009, pp. 235-236)

Apesar das transformações advindas da difusão dos Estudos Pós-Coloniais e dos Estudos Subalternos, na América Latina, por exemplo, diferentes autores (Grosfoguel, 
2008; Lander, 2000; Maldonado-Torres, 2007; Mignolo, 2007; Quijano, 2005) têm discutido acerca da necessidade de descolonização do conhecimento, de maneira a pensar o mundo para além do olhar europeu ou de outros lugares, mas sob um olhar contextualizado a partir da história colonial latino-americana. Tal perspectiva, conhecida por diferentes denominações, como Opção Decolonial, Teoria Decolonial ou Giro Decolonial, abarca conceitos diversos, de entre os quais, modernidade/colonialidade e colonialidade do poder, os quais consideramos que podem ser úteis para refletirmos sobre as possibilidades de diálogo intercultural na Europa em tempos atuais.

Com relação ao primeiro conceito, modernidade/colonialidade, como o próprio nome sugere, significa alertar para as imbricações existentes entre a modernidade e a colonialidade, sendo essa última parte essencial da primeira. Assim, conforme argumenta Porto-Gonçalves (2011, p. 42), a subjugação dos povos originários da América, junto à escravidão e ao tráfico de negros africanos, que foram levados a esse continente, contribuíram para a consolidação da centralidade da Europa, fazendo com que o sistema-mundo moderno se construísse junto à colonialidade, constituindo-se, portanto, um "sistema-mundo moderno-colonial". Desse modo, a expressão "modernidade/colonialidade", conforme discorre Castro-Gómez (2005), se constitui numa reelaboração da ideia de sistema-mundo de Wallerstein (1974), que traz para o centro do debate, porém, o aspecto da colonialidade, bem como evidencia o caráter patriarcal, capitalista, eurocêntrico da configuração desse sistema-mundo (Grosfoguel, 2008).

Já a colonialidade do poder foi uma ideia proposta por Quijano (2005), segundo a qual, mesmo com o fim do colonialismo, as relações coloniais no âmbito econômico, político e social não acabaram. Assim, esse termo demarca "um processo fundamental de estruturação do sistema-mundo moderno/colonial, que articula os lugares periféricos da divisão internacional do trabalho com a hierarquia étnico-racial global e com a inscrição de migrantes do Terceiro Mundo na hierarquia étnico-racial das cidades metropolitanas globais" (Grosfoguel, 2008, p. 126). Esse conceito teve depois o seu uso ampliado por diferentes autores, como Maldonado-Torres (2007) e Lander (2000), passando a ideia de colonialidade a ser utilizada também como uma colonialidade do ser e do saber. A associação entre essas três formas de colonialidade é visível, por exemplo, durante o processo de dominação colonial europeia, a partir do qual, a fim de justificar tal dominação, foi desenvolvido um conhecimento sobre o Outro, que permitiu construir e reproduzir uma imagem deste Outro colonizado racializado, de forma a despojá-lo da sua condição de ser.

Após essa breve caracterização dos Estudos Culturais e de alguns conceitos derivados de perspectivas teóricas construídas em diferentes contextos, procederemos a uma breve discussão sobre os principais pontos de convergência entre os Estudos Culturais e a Psicologia Social.

\section{A Psicologia Social e os Estudos Culturais}

Tanto os Estudos Culturais, quanto as abordagens com as quais trabalhamos dentro da Psicologia Social, concedem grande importância à interdisciplinaridade e ao 
compromisso ético e político na condução dos debates e investigações realizados a partir destas perspectivas. Possuem, ainda, em comum a oposição ao essencialismo, ao ahistoricismo e ao pensamento dicotômico, destacando as continuidades e mudanças envolvidas no processo histórico de construção da realidade, a partir das interações que os indivíduos desenvolvem em seu mundo social, em diferentes contextos históricos e culturais.

Além disso, apesar da heterogeneidade existente no que diz respeito a conceitos e perspectivas analíticas possíveis no âmbito dos Estudos Culturais, Hall (1996) chama a atenção para a necessidade de buscar alguns aspectos em comum que caracterizem esse projeto, sem, no entanto, deixar de reconhecer as particularidades de cada contexto e as diferentes apropriações que podem existir. Nesse sentido, Spink (2003), ao escrever o prefácio do livro Psicologia Social nos Estudos Culturais: perspectivas e desafios para uma nova Psicologia Social, discute que esse campo se define em torno de dois conceitos centrais: identidade e cultura. Tal importância atribuída ao fenômeno cultural e aos processos identitários é um dos pontos centrais de convergência entre a Psicologia Social e os Estudos Culturais (Spink, 2003), para além também das outras características em comum que mencionamos anteriormente.

Com relação ao conceito de cultura, este é um fator de aproximação, visto que a realização de uma pesquisa psicossocial almeja "perceber as intersecções entre as estruturas sociais, os grupos sociais, a cultura, a história e as relações que as pessoas constroem e passam a ser construídas por elas" (Guareschi, Medeiros \& Bruschi, 2003, p. 32). Uma das concepções de cultura que teve importante influência no processo inicial de construção do campo dos Estudos Culturais foi a definição proposta por Williams (1958/2002), segundo a qual a cultura é entendida como algo ordinário, afastando-se de visões elitistas existentes sobre este conceito (Escosteguy, 2003). Tal perspectiva contribuiu para ampliar o conceito de cultura, na medida em que passou a abranger também "as formas nas quais os rituais da vida cotidiana, instituições e práticas, ao lado das artes, são constitutivos de uma formação cultural" (Escosteguy, 2003, pp. 61-62).

No desenvolvimento da linha de discussão dos Estudos Culturais, notadamente a partir de trabalhos como os de Stuart Hall, a cultura pode ser compreendida "tanto como uma forma de vida (ideias, atitudes, linguagens, práticas, instituições e estruturas de poder), quanto como toda uma gama de práticas culturais (formas, textos, cânones, arquitetura, mercadorias produzidas em massa)" (Guareschi et al., 2003, p. 34, grifos dos autores). Dada a complexidade inerente ao conceito de cultura, portanto, é importante que diferentes áreas do conhecimento sejam conjugadas com o intuito de prover uma melhor compreensão dos fenômenos envolvidos no estudo dos processos culturais, o que pode ser alcançado, por exemplo, a partir da articulação entre Estudos Culturais e Psicologia Social (Guareschi et al., 2003).

Já quanto ao conceito de identidade, a aproximação entre a Psicologia Social e os Estudos Culturais também é efetivada a partir de uma visão antiessencialista deste conceito, sustentando a ideia de que a identidade é plural, fruto de processos de construção culturais e históricos e que se constrói em relação a diversos Outros (por 
exemplo, Bernardes \& Hoenisch, 2003; Tajfel, 1982b, 1983; Woodward, 2000). Tal concepção corrobora com a concepção de identidade social, segundo a Teoria da Identidade Social, entendendo-a como um processo relacional, podendo os indivíduos possuir tantas identidades quantos sejam os grupos aos quais sentem pertencer. Segundo essa perspectiva, trabalha-se com a ideia de grupo psicológico: pertencer a um grupo pressupõe uma pertença emocional, valorativa e cognitiva, e não apenas um compartilhamento de espaços comuns (Tajfel, 1982a, 1982b, 1983).

Além disso, também o conceito de representação social - entendida como forma de saber do senso comum, que permite entender e explicar a realidade, facilitando os processos comunicativos (Moscovici, 1961/2004) - pode configurar-se como um campo dinâmico de possibilidades de estudos sobre diferentes questões, contribuindo para a articulação entre diferentes áreas do conhecimento (Cabecinhas, 2009), como a Psicologia Social, a Sociologia, os Estudos Culturais, entre outras.

Estes são, portanto, alguns dos conceitos, fenômenos e processos que se entrelaçam na articulação entre Estudos Culturais e Psicologia Social. Tal articulação torna-se ainda mais profícua quando avançamos as discussões acerca da ideia de interculturalidade, conforme faremos a seguir.

\section{Do multiculturalismo À interculturalidade: Contributos da Psicologia Social E dos Estudos Culturais}

As mudanças provocadas pelos processos de globalização, especialmente a partir do final do século XX, fazem com que o conceito de cultura também sofra algumas modificações de modo a incluir a noção de interculturalidade. Dessa forma, Appadurai (2001) discute o uso da cultura como um adjetivo, como o cultural, como um terreno de diferenças, contrastes e comparações. Canclini (1999/2010), também fazendo uso dessa concepção proposta por Appadurai, complementa que este cultural se refere a processos por meio dos quais

representamos e instituímos imaginariamente o social, concebemos e administramos as relações com os outros, ou seja, as diferenças, ordenamos sua dispersão e sua incomensurabilidade por meio de uma delimitação que flutua entre a ordem que possibilita o funcionamento da sociedade (local e global) e os atores que a abrem ao possível. (Canclini, 1999/2010, pp. 57-58)

Desse modo, observa-se uma tendência em diversas áreas, como Psicologia, Sociologia, Estudos Culturais, entre outras, a falar em culturas, no plural, distanciando-se do monoculturalismo e da epistemologia monocultural que durante muito tempo marcou a modernidade, e mudando o foco para o multiculturalismo (Veiga-Neto, 2003).

Com relação a esta última expressão, trata-se de um conceito polissêmico, podendo haver, ainda, diferentes termos usados para descrever a situação das sociedades plurais atuais. Por exemplo, segundo Hall (2000), há uma diferença entre os termos multicultural e multiculturalismo, pois enquanto o primeiro é qualificativo, descrevendo as 
características de sociedades nas quais convivem diferentes culturas, o segundo termo, de cunho substantivo, diz respeito a políticas e/ou estratégias que possam ser utilizadas para lidar com problemas relativos à diversidade, advindos das sociedades multiculturais (Hall, 2000). Considerando-se a polissemia deste conceito, discutida por diversos autores (por exemplo, André, 2012; Candau, 2008; Damázio, 2008; Gandin \& Hypolito, 2003; Hall, 2000; Lopes, 2012; Santos \& Nunes, 2003), podem existir diferentes tipos de multiculturalismo, de acordo com a conceituação adotada. Por exemplo, segundo McLaren (1997), citado por Damázio (2008), há quatro tipos de multiculturalismo: crítico, conservador, humanista liberal e liberal de esquerda. Já Hall (2000), considerando também a visão de McLaren, lista seis tipos principais de multiculturalismo, quais sejam: crítico ou "revolucionário", liberal, conservador, pluralista, comercial e corporativo (público ou privado)'.

Boaventura de Sousa Santos, em entrevista a Gandin e Hypolito (2003), também discute sobre a importância de se distinguir entre "as formas conservadoras ou reacionárias do multiculturalismo e as formas progressistas e inovadoras" (Gandin \& Hypolito, 2003, p. 11), sendo que, dentre as formas conservadoras está o multiculturalismo colonial, em que não há um reconhecimento de fato de outras culturas, desenvolvendo-se uma postura assimilacionista. Já entre as formas progressistas, encontra-se o multiculturalismo emancipatório ou a interculturalidade descolonial, conforme o autor tem proposto recentemente (por exemplo, Santos, 2016), que se configura como uma proposta pós-colonial, de cunho antiessencialista, e segundo a qual parte-se da ideia de que "as culturas são todas elas diferenciadas internamente e, portanto, é tão importante reconhecer as culturas umas entre as outras, como reconhecer diversidade dentro de cada cultura e permitir que dentro da cultura haja resistência, haja diferença" (Gandin \& Hypolito, 2003, p. 13). No entanto, conforme ressalva Santos nesta mesma entrevista, há que cuidar para que

não caiamos na armadilha de aceitar que reconhecimento vá ao ponto de estabelecer critérios de autenticidade, o que faz com que as culturas passem a ser apenas culturas de testemunho. E, portanto, sobre as mulheres, sobre o movimento das mulheres e sobre a discriminação contra as mulheres, só possam falar mulheres; pelos negros e pela discriminação contra os negros, só possam falar negros. A ideia da autenticidade de testemunho é, no meu entender, uma das formas que pode levar a um desenvolvimento de um novo apartheid cultural e que podia ser realizado por meio de um radicalismo excessivo, porque permitiria criar igualdade, mas em separação. (Gandin \& Hypolito, 2003, p. 13)

A partir dessas considerações acerca dos diferentes usos do multiculturalismo, Santos e Nunes (2003) enumeram algumas críticas referentes a este conceito. Uma dessas críticas é a própria definição de cultura que utiliza, visto que sobre esta também

\footnotetext{
' Para fins deste artigo não serão aprofundados estes conceitos, visto que ultrapassariam os propósitos da presente reflexão. Para mais informações ver, por exemplo: Damázio (2008); Hall (2000).
} 
há diferentes conceitos; outra refere-se à ideia do multiculturalismo como sendo um conceito eurocêntrico, que desconsidera as diferentes formas que o mesmo pode assumir em diferentes países e regiões do mundo. Critica-se, ainda, o multiculturalismo como sendo uma "forma de racismo negada" (Zizek, 1998, p. 22), ligada ao capitalismo multinacional (Zizek, 1998). Assim, este se constitui como um conceito, por vezes, "apolítico" e "descritivo", a partir do qual "o apelo à noção de 'tolerância' não exige um envolvimento ativo com os 'outros' e reforça o sentimento de superioridade de quem fala de um autodesignado lugar de universalidade" (Santos \& Nunes, 2003, p. 31).

Levando-se em consideração essas críticas, muitos autores propõem a substituição do termo multiculturalismo por interculturalismo ou interculturalidade (por exemplo, Candau, 2008; Damázio, 2008; Lopes, 2012). Neste trabalho utilizamos o termo interculturalidade. Entretanto, também com relação a este conceito, há diferentes entendimentos. Segundo Walsh $(2010,2012)$, a interculturalidade pode ser entendida a partir de três perspectivas: relacional, funcional e crítica. A perspectiva relacional limita a concepção da interculturalidade aos contatos, às relações interpessoais, minimizando as tensões envolvidas nessas relações, isto é, as relações de poder, dominação e colonialidade. A perspectiva funcional reconhece a diversidade e a diferença, porém a partir de uma lógica que é funcional ao sistema social capitalista neoliberal vigente, ou seja, visa tolerar e/ou incorporar o diferente às matrizes sociais já estabelecidas, sem questionar as causas das assimetrias de poder e das desigualdades sociais. Finalmente, a perspectiva crítica questiona a ordem social vigente, compreendendo a interculturalidade como um processo e um projeto, que parte das experiências dos "subalternos", daqueles que foram vítimas de xenofobia e racismo, a fim de buscar a transformação das estruturas sociais, institucionais e epistêmicas, (re)criando diferentes formas de ser, estar, de se relacionar (Walsh, 2010, 2012), que impliquem não apenas o mero reconhecimento e tolerância de outras culturas, mas também a sua valorização, em diálogo e interação mútuos (Canclini, 1999/2010). É a partir desta perspectiva crítica, decolonial, que entendemos a interculturalidade.

Dessa forma, para compreendermos os processos psicossociais envolvidos no diálogo intercultural nas sociedades plurais contemporâneas é importante, por conseguinte, conjugarmos diferentes saberes, como o fazemos neste artigo, a fim de propiciar uma análise mais contextualizada e aprofundada. Nesse sentido, ao discutirmos sobre diálogo intercultural, devemos discutir também sobre identidade e alteridade, processos que fazem parte da relação com o Outro.

A relação com o Outro, com a alteridade, com a diferença é uma questão histórica e que, atualmente, na dialética entre as realidades locais e as globalizações, apresenta diferentes contornos e convida a novas compreensões e reflexões (Jovchelovitch, 2002). A construção da identidade social dos indivíduos e das suas representações sociais sobre diferentes objetos se dá a partir dessa relação com o alter (indivíduos e/ou grupos), de modo que tal encontro com o Outro envolve o contato com o não familiar (Moscovici, 2000/2010), com aqueles Outros que não se encaixam nos nossos padrões cognitivos, morais, estéticos de mundo, aqueles que obscurecem e confundem o que antes 
nos parecia tão nítido e simples: as fronteiras, os limites, as identificações, ou seja, confundem, geram desconforto, estranhamento (Bauman, 1997), desestabilizando a ordem existente e almejada (Joffe, 2002). Porém, esse estranhamento gerado pela diferença do Outro "surpreende mais na medida em que, na verdade, o outro não é tão diferente, mas sim um semelhante que não conseguimos situar" (Arruda, 2002, pp. 19-20). A tentativa de situar os Outros envolve a compreensão da alteridade "como produto e processo psicossocial" (Jodelet, 2002), de forma que entram em cena diferentes processos presentes na construção das representações sociais (Moscovici, 1961/2004) e das identidades sociais (Tajfel, 1982b, 1983), a fim organizar as informações recebidas do meio e ancorar o não familiar em categorias mais familiares (Moscovici, 1961/2004).

Assim, essas interações com diferentes Outros tornam-se ainda mais evidentes no contexto atual de globalizações (André, 2012), que provoca mudanças não apenas com relação a aspectos econômicos, como o aumento da movimentação de bens, mas também profundas transformações em termos socioculturais. Desse modo, tais processos de globalização, quando acompanhados por outros fenômenos, como as migrações, fazem com que as fronteiras nacionais e identitárias sejam redefinidas (Beck, 2002; Hall, 2000), intensificando a pluralização das sociedades. Nesse sentido, as migrações possibilitam o contato entre pessoas de diferentes culturas e tornam saliente o processo de comparação social, mecanismo basilar à construção da identidade social (Tajfel, 1982b, 1983). Tal processo possibilita o surgimento de diferentes classificações e comparações que os indivíduos possam estabelecer entre os variados grupos nacionais e/ou supranacionais com os quais se relacionam e aos quais podem se considerar pertencentes, complexificando, portanto, as distinções entre "nós" e "eles" (Chryssochoou, 2000).

O maior contato intercultural entre diferentes grupos, como o que presenciamos, por exemplo, em contexto europeu, também faz com que as memórias coletivas ou as representações sociais da história (Licata \& Klein, 2005; Liu \& Hilton, 2005) se tornem mais plurais, desafiando as representações já conhecidas dentro de um mesmo grupo (Liu \& Hilton, 2005). Esse é o caso, por exemplo, de grupos supranacionais, como a União Europeia, visto que, ainda que os diferentes países que a compõem tenham suas especificidades e, ainda que existam marcadas assimetrias de poder entre eles, parece ser importante que partilhem alguns elementos em comum nas representações sociais da história deste grupo e que as lideranças políticas levem em consideração essas representações ao formularem políticas que sejam comumente aceitas entre os envolvidos e condizentes a uma realidade comum (Liu \& Hilton, 2005). A Psicologia Social e os Estudos Culturais possuem interessantes recursos teóricos para analisar as (re)construções dessas memórias coletivas e das relações de colonialidade que possam estar envolvidas nessas negociações a partir das relações intergrupais atuais.

Além destas contribuições para a análise de processos identitários e representacionais envolvidos nas relações intergrupais, a Psicologia Social também dispõe de diferentes modelos para o estudo das dinâmicas identitárias envolvidas nas relações entre subgrupos (por exemplo, países europeus) e grupos supraordenados (por exemplo, Europa) (dentre estes, ver: Hornsey \& Hogg, 2000; Wenzel, Mummendey \& Waldzus, 
2007); e de modelos para o estudo de estratégias interculturais ou estratégias de aculturação envolvendo diferentes grupos, como migrantes e sociedade do país de destino (ver: Berry, 2001, 2011).

O estudo dessas relações entre diferentes Outros torna-se ainda mais profícuo quando associado à concepção de interculturalidade crítica (Walsh, 2010, 2012), a partir da perspectiva decolonial, sobre a qual discorremos anteriormente. Tal concepção mostra-se importante, sobretudo, para superar alguns desafios atuais na configuração de espaços de diálogo intercultural, como os discutidos, por exemplo, por Oliveira (2017, p. 29). Segundo este autor, para além das discussões sobre a dimensão teórica do conceito de interculturalidade, é necessário refletir acerca da sua dimensão prática, acerca dos usos que são feitos da interculturalidade. Nesse sentido, conforme argumenta o autor, tem sido frequente em diferentes países europeus a adoção de uma lógica "consumista" da interculturalidade, de modo a haver uma "festivalização da diversidade" e uma "marketização" dos espaços dos centros de algumas cidades, a partir da incorporação dos migrantes e dos seus traços culturais para estes fins.

Também Cabecinhas e Cunha (2017) alertaram para a importância de irmos além da compreensão da diversidade como algo folclórico, por exemplo, a partir do consumo da gastronomia, da música e da dança de diferentes países, e compreendermos que, para que haja diálogo com o Outro, não basta uma mera tolerância ou assimilação do Outro, é necessário que haja verdadeira interação e transformações recíprocas. Tal contexto nos remete para a imprescindibilidade de reafirmarmos a interculturalidade não apenas como o reconhecimento da diversidade cultural, mas também, como o convívio de forma igualitária e respeitosa entre diferentes Outros dentro de um dado território.

\section{ConCLUSÕES}

Neste artigo apresentamos algumas discussões acerca das possibilidades existentes no uso conjugado de conceitos e categorias dos Estudos Culturais e da Psicologia Social para a análise das relações intergrupais e da construção de espaços de diálogo intercultural na Europa contemporânea. Sabemos, contudo, que outras análises e interlocuções são possíveis, de modo que não tivemos a intenção de esgotar as reflexões acerca de fenômenos tão complexos como os que aqui abordamos, mas sim, de (re) iniciarmos alguns debates, que possam nos levar a tantos outros, no sentido de (re) criarmos saberes, técnicas e instituições que permitam a construção de pontes de diálogo entre os diferentes Outros em constante interação não apenas em contexto europeu, mas também em outras partes do mundo.

Assim, ratificamos a importância do diálogo intercultural, como um desafio a ser cumprido (Cabecinhas \& Cunha, 2017), o qual é favorecido ao ouvir o que os Outros têm a dizer sobre eles mesmos e acerca do que pensam sobre o mundo. Essa escuta pode propiciar o desenvolvimento de maior abertura à pluralidade de culturas e saberes, além de maior empatia com relação ao Outro, para que haja reconhecimento, trocas recíprocas e transformação mútua. / 


\section{FinANCIAMENTO}

Esta pesquisa contou com o apoio da Coordenação de Aperfeiçoamento de Pessoal de Nível Superior - CAPES/Brasil, a partir de uma bolsa de doutorado pleno no exterior (Número do Processo: 1690/13-2) concedida à primeira autora.

\section{REFERÊNCIAS}

André, J. M. (2012). Interpretações do mundo e multiculturalidade: incomensurabilidade e diálogo entre culturas. In J. M. André (Ed.), Multiculturalidade, identidades e mestiçagem: o diálogo intercultural nas ideias, na política, nas artes e na religião (pp. 73-104). Coimbra: Palimage.

Appadurai, A. (2001). La modernidad desbordada: dimensiones culturales de la globalización. Buenos Aires: Ediciones Trilce.

Arruda, A. (2002). O ambiente natural e seus habitantes no imaginário brasileiro. In A. Arruda (Ed.), Representando a alteridade (pp. 17-46). Petrópolis: Vozes.

Baptista, M. M. (2009). Estudos culturais: o quê e o como da investigação. Carnets - Cultures littéraires: nouvelles performances et développement, [nº spécial], 451-461. Retirado de http://revistas.ua.pt/index. php/Carnets/article/view/466/422

Barker, C. (2004). The SAGE dictionary of cultural studies. Londres: Sage Publications.

Bauman, Z. (1997). The making and unmaking of strangers. In P. Werbner \& T. Modood (Eds.), Debating cultural hybridity: multi-cultural identities and the politics of anti-racism (pp. 46-57). Londres e New Jersey: Zed Books.

Beck, U. (2002). The cosmopolitan society and its enemies. Theory, Culture Q Society, 19(1-2), 17-44. https:// doi.org/10.1177/026327640201900101

Bernardes, A. G. \& Hoenisch, J. C. D. (2003). Subjetividade e identidades: possibilidades de interlocução da Psicologia Social com os Estudos Culturais. In N. M. F. Guareschi \& M. E. Bruschi (Eds.), Psicologia Social nos Estudos Culturais: perspectivas e desafios para uma nova Psicologia Social (pp. 95-126). Petrópolis: Vozes.

Berry, J. W. (2001). A psychology of immigration. Journal of Social Issues, 57(3), 615-631. https://doi. org/10.1111/0022-4537.00231

Berry, J. W. (2011). Integration and multiculturalism: ways towards social solidarity. Papers on Social Representations, 20, 2.1-2.21. Retirado de http://psych.lse.ac.uk/psr/PSR2011/20_02.pdf

Bhabha, H. K. (1990). Nation and narration. Londres: Routledge.

Bhabha, H. K. (1994/2005). O local da cultura. Belo Horizonte: UFMG.

Cabecinhas, R. (2009). Investigar representações sociais: metodologias e níveis de análise. In M. M. Baptista (Ed.), Cultura: metodologias e investigação (pp. 51-66). Lisboa: Ver o Verso Edições.

Cabecinhas, R. \& Cunha, L. (2017). Introdução: da importância do diálogo ao desafio da interculturalidade. In R. Cabecinhas \& L. Cunha (Eds.), Comunicação intercultural: perspectivas, dilemas e desafios (pp. 7-12). Vila Nova de Famalicão: Húmus.

Canclini, N. G. (1999/2010). A globalização imaginada. São Paulo: Iluminuras. 
Candau, V. M. (2008). Direitos humanos, educação e interculturalidade: as tensões entre igualdade e diferença. Revista Brasileira de Educação, 13(37), 45-56. http://dx.doi.org/10.1590/ S1413-24782008000100005

Castro-Gómez, S. (2005). Ciencias sociais, violencia epistêmica e o problema da "invencao do outro". In E. Lander (Ed.), A colonialidade do saber: eurocentrismo e ciências sociais. Perspectivas latino-americanas (pp. 8o-87). Ciudad Autónoma de Buenos Aires: Colección Sur Sur, CLACSO.

Chryssochoou, X. (2000). Memberships in a superordinate level: re-thinking European Union as a multinational society. Journal of community \& Applied Social Psychology, 10(5), 403-420. https://doi. org/10.1002/1099-1298(200009/10) 10:5<403::AID-CASP597>3.0.CO;2-4

Damázio, E. S. P. (2008). Multiculturalismo versus interculturalismo: por uma proposta intercultural do Direito. Desenvolvimento em Questão, 6(12), 63-86. https://doi.org/10.21527/2237-6453.2008.12.63-86

Escosteguy, A. C. D. (2003). Os Estudos Culturais e a constituição de sua identidade. In N. M. F. Guareschi \& M. E. Bruschi (Eds.), Psicologia Social nos Estudos Culturais: perspectivas e desafios para uma nova Psicologia Social (pp. 51-74). Petrópolis: Vozes.

Fanon, F. (1961/2004). The wretched of the Earth. Nova lorque: Grove Press.

Fanon, F. (1952/2008). Pele negra, máscaras brancas. Salvador: EDUFBA.

Gandin, L. A. \& Hypolito, Á. M. (2003). Dilemas do nosso tempo: globalização, multiculturalismo e conhecimento (entrevista com Boaventura de Sousa Santos). Currículo sem Fronteiras, 3(2), 5-23. Retirado de http://www.curriculosemfronteiras.org/volziss2articles/boaventura.pdf

Gros, C. (2002). América Latina: identidade o mestizaje? La nación em juego. Desacatos, 10, 127-147. Retirado de de http://www.redalyc.org/articulo.oa?id=13901009

Grosfoguel, R. (2008). Para descolonizar os estudos de economia politica e os estudos pós-coloniais: transmodernidade, pensamento de fronteira e colonialidade global. Revista Crítica de Ciências Sociais, 80, 115-147. Retirado de https://dialnet.unirioja.es/servlet/articulo?codigo=2763903

Guareschi, N. M. F., Medeiros, P. F. \& Bruschi, M. E. (2003). Psicologia Social e Estudos Culturais: rompendo fronteiras na produção do conhecimento. In N. M. F. Guareschi, \& M. E. Bruschi (Eds.), Psicologia Social nos Estudos Culturais: perspectivas e desafios para uma nova psicologia social (pp. 23-49). Petrópolis: Vozes.

Hall, S. (1996). Cultural studies and the politics of internationalization: an interview with Stuart Hall by Kuan-Hsing Chen. In D. Morley, \& K-H Chen (Eds.), Stuart Hall - critical dialogues in cultural studies (pp. 261-274). Nova lorque/Londres: Routledge.

Hall, S. (2000). Conclusion: the multi-cultural question. In B. Hesse (Ed.), Un/settled multiculturalisms: diasporas, entanglements, 'transruptions' (pp. 209-241). Londres: Zed Books.

Hornsey, M. J. \& Hogg, M. A. (2000). Assimilation and diversity: an integrative model of subgroup relations. Personality and Social Psychology Review, 4(2),143-156. https://doi.org/10.1207/S15327957PSPRo4O2_03

Jodelet, D. (2002). A alteridade como produto e processo psicossocial. In A. Arruda (Ed.), Representando a alteridade (pp. 47-67). Petrópolis: Vozes.

Joffe, H. (2002). Degradação, desejo e “o outro". In A. Arruda (Ed.), Representando a alteridade (pp. 109-128). Petrópolis: Vozes.

Jovchelovitch, S. (2002). Re(des)cobrindo o outro - para um entendimento da alteridade na teoria das representações sociais. In A. Arruda (Ed.), Representando a alteridade (pp. 69-82). Petrópolis: Vozes. 
Lander, E. (Ed.) (2000). La colonialidad del saber: eurocentrismo y ciencias sociales. Perspectivas latinoamericanas. Buenos Aires, Argentina: Consejo Latinoamericano de Ciencias Sociales. Retirado de http://bibliotecavirtual.clacso.org.ar/clacso/sur-sur/20100708034410/lander.pdf

Licata, L. \& Klein, O. (2005). Regards croisés sur un passé commun: anciens colonisés et anciens coloniaux face à l'action belge au Congo. In M. Sanchez-Mazas \& L. Licata (Eds.), L’Autre: regards psychosociaux (pp. 241-277). Saint-Martin d'Hères: Presses Universitaires de Grenoble.

Liu, J. H. \& Hilton, D. (2005). How the past weighs on the present: towards a social psychology of histories. British Journal of Social Psychology, 44, 537-556. https://doi.org/10.1348/014466605X27162

Lopes, A. M. D. (2012). Da coexistência à convivência com o outro: entre o multiculturalismo e a interculturalidade. Revista Interdisciplinar de Mobilidade Humana, 38, 67-81. http://dx.doi.org/10.1590/ S1980-85852012000100005

Maldonado-Torres, N. (2007). Sobre la colonialidad del ser: contribuciones al desarrollo de un concepto. In S. Castro-Gómez \& R. Grosfoquel (Eds.), El giro decolonial. Reflexiones para una diversidad epistémica más allá del capitalismo global (pp. 127-167). Bogotá: Siglo del Hombre.

Martins, M. L., Sidoncha, U. \& Bandeira, M. (2017). Nota introdutória - Estudos Culturais, cidadania e democracia. Revista Lusófona de Estudos Culturais, 4(2), 7-11. Retirado de http://hdl.handle. net $/ 1822 / 54186$

Mignolo, W. D. (2007). La idea de América Latina: la herida colonial y la opción decolonial. Barcelona: Editorial Gedisa.

Moscovici, S. (1961/2004). La psychanalyse son image et son public. Paris: Presses Universitaires de France.

Moscovici, S. (2000/2010). O fenômeno das representações sociais. In G. Duveen (Ed.), Representações sociais: investigações em Psicologia Social (pp. 29-109). Petrópolis: Vozes.

Neves, R. C. (2009). Os Estudos Pós-Coloniais: um paradigma de globalização. Babilónia - Revista Lusófona de Línguas, Culturas e Tradução, 6/7, 231-239. Retirado de http://hdl.handle.net/10437/2111

Oliveira, N. (2017). Do multiculturalismo ao interculturalismo: um novo modo de incorporação da diversidade cultural? Revista Ambivalência, 5(9), 10-35. https://doi.org/10.21665/2318-3888.v5n9p10-35

Porto-Gonçalves, C. W. (2011). Abya Yala, el descubrimiento de América. In N. Giarraca (Ed.), Bicentenarios (otros), trasiciones y resistencias (pp. 39-46). Buenos Aires: Uma Ventana.

Prysthon, A. (2004). Interseções da teoria crítica contemporânea: estudos culturais, pós-colonialismo e comunicação. Revista e-Compós, 1, 1-19. Retirado de https://revistas.ufrj.br/index.php/eco_pos/article/ view/1119

Quijano, A. (2005). Colonialidade do poder, eurocentrismo e América Latina. In E. Lander (Ed.), A colonialidade do saber: eurocentrismo e ciências sociais. Perspectivas latino-americanas (pp. 227-278). Ciudad Autónoma de Buenos Aires: Colección Sur Sur, CLACSO.

Said, E. W. (1978/2007). Orientalismo - o Oriente como invenção do Ocidente. São Paulo: Companhia de Bolso.

Santos, B. S. (2016). A difícil democracia: reinventar as esquerdas. São Paulo: Boitempo.

Santos, B. S. \& Nunes, J. A. (2003). Introdução: para ampliar o cânone do reconhecimento, da diferença e da igualdade. In B. S. Santos (Ed.), Reconhecer para libertar: os caminhos do cosmopolitismo multicultural (pp. 25-68). Rio de janeiro: Civilização Brasileira. 
Spink, M. J. P. (2003). Prefácio. In N. M. F. Guareschi \& M. E. Bruschi (Eds.), Psicologia Social nos Estudos Culturais: perspectivas e desafios para uma nova psicologia social (pp. 9-19). Petrópolis: Vozes.

Spivak, G. C. (1985/2010). Pode o subalterno falar? Belo Horizonte: Editora da UFMG.

Tajfel, H. (1982a). Comportamento intergrupo e psicologia social da mudança. In A. F. Barroso, B. M. Silva, J. Vala, B. M. Monteiro \& M. H. Castro (Eds.), Mudança social e psicologia social (pp. 13-24). Lisboa: Livros horizonte.

Tajfel, H. (1982b). Grupos humanos e categorias sociais. Vol. 1. Lisboa: Livros Horizonte.

Tajfel, H. (1983). Grupos humanos e categorias sociais. Vol. 2. Lisboa: Livros Horizonte.

Veiga-Neto, A. (2003). Cultura, culturas e educação. Revista Brasileira de Educação, 23, 5-15. http://dx.doi. org/10.1590/S1413-24782003000200002

Wallerstein, I. (1974). The modern world system. Vol. 1. Nova Iorque: Academic Press.

Walsh, C. (2010). Interculturalidad crítica y educación intercultural. In J. Viaña, L. Tapia \& C. Walsh (Eds.), Construyendo interculturalidad crítica (pp. 75-96). La Paz: Instituto Internacional de Integración, Convenio Andrés Bello.

Walsh, C. (2012). Interculturalidad crítica y (de)colonialidad. Ensayos desde Abya Yala. Quito: Editorial Abya-Yala, Serie Pensamiento decolonial.

Wenzel, M., Mummendey, A. \& Waldzus, S. (2007). Superordinate identities and intergroup conflict: the ingroup projection model. European Review of Social Psychology, 18(1), 331-372. https://doi. org/10.1080/10463280701728302

Williams, R. (1958/2002). Culture is ordinary. In B. Highmore (Ed.), The everyday life reader (pp. 91-100). Londres: Routledge.

Woodward, K. (2000). Identidade e diferença: uma introdução teórica e conceitual. In T. T. Silva (Ed.), Identidade e diferença: a perspectiva dos Estudos Culturais (pp. 7-72). Petrópolis: Vozes.

Zizek, S. (1998). Multiculturalismo o la lógica cultural del capitalismo multinacional. In F. Jameson \& S. Zizek (Eds.), Estudios culturales. Reflexiones sobre el multiculturalismo (pp. 137-188). Buenos Aires: Paidós.

\section{NOTAS BIOGRÁFICAS}

Julia Alves Brasil é doutorada em Estudos Culturais pela Universidade do Minho/ Portugal. Psicóloga, com Mestrado em Psicologia pela Universidade Federal do Espírito Santo (UFES)/Brasil. Investigadora colaboradora do Centro de Estudos de Comunicação e Sociedade (CECS)/Universidade do Minho. Pesquisadora de pós-doutorado em Psicologia Social na UFES.

ORCID: https://orcid.org/oooo-0003-0445-1207

Email: juliaalvesbrasil@gmail.com

Av. Fernando Ferrari, 514, Goiabeiras, Vitória - ES, Brasil. CEP: 29075-910

Rosa Cabecinhas é Professora Associada no Instituto de Ciências Sociais da Universidade do Minho e investigadora do Centro de Estudos de Comunicação e 
Sociedade. Atualmente é diretora do Programa Doutoral em Estudos Culturais na mesma universidade.

ORCID: https://orcid.org/oooo-0002-1491-3420

Email: cabecinhas@ics.uminho.pt

Instituto de Ciências Sociais, Universidade do Minho, Campus de Gualtar, 4710057, Braga, Portugal

* Submetido: 14/09/2018

* Aceite: 18/12/2018 